\title{
Heinz Karger zum 10. November 1955
}

\section{$/ \mathrm{j} \wedge \times \wedge_{\dot{\mathrm{i}}}$}

Am 10. November begeht Herr Dr. H. Karger seinen 60. Geburtstag. Als sich nach dem letzten Weltkriege die Aufgabe erneut stellte, die hämatologische Forschung auf europäischem Gebiete in einem internationalen, mehrsprachigen Archiv in repräsentativer Form zu vereinigen, urn damit den Anschluß an die übrigen Kontinente wieder herzustellen, fanden wir beim heutigen Jubilar voiles Ver-ständnis und große Bereitwilligkeit für unsere Ideen. Mit dem ihm eigenen verlegerischen Geschick, seiner reichen Erfahrung und seinem steten Interesse für unser Fachgebiet, gelang es ihm rasch, unseren Wünschen zu entsprechen und zum Gedeihen der jungen Zeitschrift Wesentliches beizutragen. Sosind die«Acta Haematologica»zu einemführenden Organ auf dem Gebiete der Hämatologie herangewachsen. Dem Verleger, Herrn Dr. Heinz Karger, gebührt dafür der besondere Dank der Redaktion. Unsere Gratulationen zum Eintritt ins siebente Dezennium verbinden wir mit dem Wunsche, es möge dem Jubilar noch eine lange Periode erfolgreicher und für die Forschung fruchtbarer Tätigkeit beschie-den sein.

L. HEILMEYER

LÜ

MEULENGRACHT

S. MOESCHLIN

FREIBURG i. Br.

KØBENHAVN

SOLOTHURN

K. ROHR

G. ROSENOW

J. WALDENSTRÖM

ZURICH

\section{NEW YORK}

H. LÜDIN BASEL

LUND 